\title{
Anti-glutamate decarboxylase and other antibodies at the onset of childhood IDDM: a population-based study
}

\author{
C.F. Verge ${ }^{1}$, N. J. Howard ${ }^{1}$, M. J. Rowley ${ }^{2}$, I. R. Mackay $^{2}$, P.Z. Zimmet ${ }^{3}$, M. Egan ${ }^{1}$, H. Hulinska ${ }^{1}$, I. Hulinsky ${ }^{1}$, \\ R. A. Silvestrini ${ }^{4}$, S. Kamath ${ }^{4}$, A. Sharp ${ }^{5}$, T. Arundel ${ }^{1}$, M. Silink ${ }^{1}$ \\ ${ }^{1}$ Ray Williams Institute for Paediatric Endocrinology, Royal Alexandra Hospital for Children, Sydney, Australia \\ ${ }^{2}$ Centre for Molecular Biology, Monash University, Clayton, Melbourne, Australia \\ ${ }^{3}$ International Diabetes Institute, Caulfield, Melbourne, Australia \\ ${ }^{4}$ Institute of Clinical Pathology and Medical Research, Westmead Hospital, Sydney, Australia \\ ${ }^{5}$ Rodney Shearman Endocrinology Laboratory, Royal Prince Alfred Hospital, Sydney, Australia
}

Summary Sera obtained at diagnosis from 273 children (0-14 years) with insulin-dependent diabetes mellitus (IDDM) were studied to compare different autoantibody levels. The subjects comprise $75 \%$ of all incident cases in New South Wales, Australia, for a 2-year period (ascertainment $>99 \%$ complete). Antibodies against glutamate decarboxylase were measured by radioimmunoprecipitation, insulin autoantibodies (on 176 sera collected within 4 days of initiation of insulin therapy) by radioimmunoassay, thyroid peroxidase and antigliadin $\operatorname{Ig} \mathrm{A}$ antibodies by enzyme-linked immunoassay, and anti-endomysial $\operatorname{IgA}$ and islet cell antibodies by indirect immunofluorescence. Reference ranges for anti-glutamate decarboxylase and insulin autoantibodies were determined in a group of non-diabetic children. Of the sera $69 \%$ were positive for anti-glutamate decarboxylase, $65 \%$ for insulin autoantibodies, $71 \%$ for islet cell antibodies ( $\geqslant 20$ Juvenile Diabetes Foundation units), $10 \%$ for anti-thyroid peroxidase, $2.6 \%$ for antigliadin and $3.0 \%$ for anti-endomysial antibodies. Islet cell antibodies and insulin autoantibodies were both negative in $13.7 \%$ of the sera, while only $5.8 \%$ were negative for all three of islet cell antibodies, insulin autoantibodies and anti-glutamate decarboxylase. There was a higher frequency of anti-glutamate decarboxylase among girls than boys ( $75 \%$ vs $63 \%$, $p=0.03$ ) and a negative correlation between the level of insulin autoantibodies and age at diagnosis $(r=-0.41, p<0.0001)$. A higher frequency of antithyroid peroxidase was found with increasing age $(p=0.05)$. Higher titres of islet cell antibodies were associated with a higher frequency of both anti-glutamate decarboxylase $(p<0.0001)$ and insulin autoantibodies $(p=0.003)$. Five children $(1.8 \%)$ with clear elevations of antigliadin and anti-endomysial antibodies were found to have asymptomatic coeliac disease by small bowel biopsy. [Diabetologia (1994) 37 : 1113-1120]

Key words Autoantibodies, glutamate decarboxylase, islet cell antibodies, insulin, thyroid peroxidase, coeliac disease.
Received: 13 January 1994

and in revised form: 17 May 1994

Corresponding author: Dr. C. Verge, Barbara Davis Center for Childhood Diabetes, University of Colorado Health Sciences Center, Box B140, 4200 East 9th Avenue, Denver, CO 80262 , USA

Abbreviations: IDDM, insulin-dependent diabetes mellitus; ICA, islet cell antibodies; IAA, insulin autoantibodies; anti$\mathrm{GAD}$, antibodies against glutamate decarboxylase; anti-TPO, antibodies against thyroid peroxidase; AGA, antigliadin $\operatorname{IgA}$ antibodies; AEA, anti-endomysial antibodies; JDF U, Juvenile Diabetes Foundation units; PBS, phosphate buffered saline.
Although insulin-dependent diabetes mellitus (IDDM) appears to be a T-cell mediated disease, autoantibodies may be useful markers, in genetically susceptible individuals, of the beta-cell destruction that precedes clinical presentation [1]. These include islet cell antibodies (ICA) and insulin autoantibodies (IAA), with the recent addition of a quantitative assay for antibodies against glutamate decarboxylase (anti-GAD) [2]. We aimed to determine the frequency and levels of these and other antibodies in a large population-based group of newly-diagnosed diabetic children. Anti-GAD, determined with a quantitative assay, have not previously been studied in such a 
group and compared with other autoantibodies. Antithyroid peroxidase (anti-TPO), anti-gliadin IgA (AGA) and anti-endomysial (AEA) antibodies were also measured because of the association of IDDM with autoimmune thyroid disease and coeliac disease. This allowed the frequency of thyroid autoimmunity and asymptomatic coeliac disease to be determined among newly-diagnosed diabetic children.

\section{Subjects and methods}

Patients and sera. We established a register of incident cases of IDDM in the 0-14-year age-group in New South Wales (incidence rate 14.5 per 100,000 person years) and obtained a serum sample at diagnosis from new diabetic cases arising during a 2-year period (1990-1991). Case ascertainment for the register was over $99 \%$ complete, using two independent methods to identify the cases (physician reporting and the National Diabetes Supply Scheme) [3, 4]. A serum sample was available from $273(83.5 \%)$ of 327 cases identified by physician reporting. Serum could not be obtained from 34 additional cases identified only by the National Diabetes Supply Scheme. The completeness of ascertainment by physician reporting alone was $90.1 \%$, estimated by the capture-recapture method [3, 4]. Therefore, serum was available from an estimated $75 \%$ of all incident cases of IDDM in the population. Cases without a serum sample were not significantly different from those with a serum sample according to sex, age at diagnosis or ethnicity. The patients and/or their parents gave their informed consent and the study was approved by the Ethics Committee of the Royal Alexandra Hospital for Children.

The sera were collected as soon as possible after diagnosis (which was defined as the start of insulin therapy). The median delay between diagnosis and the collection of the serum was 3 days (interquartile range: $1-6$ days) and $91 \%$ of sera were obtained within 14 days of diagnosis. IAA levels from sera collected more than 4 days after diagnosis $(n=89)$ were excluded from the analysis. ICA and anti-GAD levels from sera collected more than 61 days after diagnosis $(n=8)$ were also excluded. The sera were stored at $-20^{\circ} \mathrm{C}$ in aliquots, to avoid multiple thawing and refreezing of the samples, which may cause a reduction in ICA titre [5].

Epidemiological data including place of residence, ethnic background and family history of IDDM was collected with a questionnaire completed by the parents of the cases. For analysis, the place of residence was classified by Statistical Division [6] and ethnic background was classified as European or nonEuropean.

Glutamate decarboxylase autoantibodies. Anti-glutamate decarboxylase (GAD) were measured on 261 samples collected within 61 days of diagnosis by a radioprecipitation assay, as previously described [2]. In brief, affinity purified porcine GAD was iodinated with ${ }^{125} \mathrm{I}$. The GAD was enzymically active and known to contain both isoforms GAD67 and GAD65. After preabsorption with pooled normal sera, $100,000 \mathrm{cpm}$ of $\left[{ }^{125} \mathrm{I}\right] \mathrm{GAD}$ was incubated overnight with test sera diluted $1: 2$ in Tris-Triton buffer $(0.02 \mathrm{~mol} / 1$ Tris, $0.15 \mathrm{~mol} / 1$ $\mathrm{NaCl}, 0.5 \%$ weight/volume TritonX-100, $\mathrm{pH} 7.4)$. $\left[{ }^{125} \mathrm{I}\right] \mathrm{GAD}-$ antibody complexes were precipitated by protein A-Sepharose and counted for radioactivity after three washes. The results were expressed as the percentage of the radioactivity precipitated by a positive reference serum, which thus had 100 units. The assay participated in the 1 st International Diabetes
Workshop (IDW) anti-GAD standardisation workshop and achieved ratings of $100 \%$ for specificity and sensitivity.

109 non-diabetic subjects, ranging in age from 0.5 to 19.1 years (median 10.6 years), were tested using this assay. These subjects were selected from patients attending an endocrine clinic, excluding those with autoimmune disease or a family history of diabetes. A third of the subjects were normal children referred for assessment of short stature, with no disease identified after detailed evaluation. The remainder of the children had non-autoimmune disorders that included congenital adrenal hyperplasia, post-irradiation growth hormone deficiency and dysmorphic syndromes. There was no difference in the anti-GAD levels between the group of normal children and the remainder. Among these non-diabetic subjects, antiGAD levels ranged from 3 to 18 units, except for two outliers with values of 35 and 56 units (Fig. 1). Values greater than the 98th percentile (18 units) were considered positive.

Islet cell antibodies. ICA were measured on 259 samples collected within 61 days of diagnosis. The assay employed indirect immunofluorescence after prolonged incubation with $4 \mu \mathrm{m}$ frozen sections of normal human pancreas from a single blood group type $\mathrm{O}$ donor. The sera to be tested were serially diluted in phosphate buffered saline (PBS) at pH 7.4 containing $4 \%$ bovine serum albumin and aprotinin (Trasylol; Bayer, Leverkusen, Germany) 2500 kallikrein inhibitor units $/ \mathrm{ml}$ [7]. The dilutions were randomised and $50 \mu \mathrm{l}$ of each was incubated on pancreatic sections in a moisture chamber for $24 \mathrm{~h}$ at room temperature. The sections were then washed and incubated for $30 \mathrm{~min}$ with fluorescein tagged sheep anti-human IgG (Silenus, Melbourne, Australia) for $30 \mathrm{~min}$. The sections were viewed under a Zeiss Axioscop 20 microscope with a $50 \mathrm{~W}$ mercury fluorescence burner and a Plan Neofluor 20/0.50 objective. Neither of two independent observers was aware of the identity or dilution of the sample being viewed. The assay was standardised through participation in the 5th IDW International Standardisation Workshop. One negative control serum and six positive control sera of known Juvenile Diabetes Foundation unit (JDF U) titres were included in each assay. For each assay a new standard line, drawn through the endpoint titre of five of the positive controls, was used to convert the end-point titres of the tested sera into JDF U. An additional positive control of 23 JDF $U$ was not used to derive the standard line, but was used to monitor the between-assay variation. The coefficient of variation of the $\log _{2}$ JDF U determined for this standard was $12 \%$. Thirty-nine non-diabetic control sera, including 31 children were tested and all were negative $(<20$ JDF U). The detection limit of the assay was consistently at least $20 \mathrm{JDF} U$ and sera with $\geqslant 20 \mathrm{JDF} U$ were considered positive. Before analysis, the results were categorised as negative, 20-39 JDF U, 40-79 JDF $\mathrm{U}$ or $\geqslant 80 \mathrm{JDF} \mathrm{U}$.

Insulin autoantibodies. IAA were measured on 176 samples collected within 4 days of the start of insulin therapy, using a competitive fluid phase radioassay [8]. The assay participated in the IAA proficiency test programme (N.K. Maclaren, Gainesville, Fla., USA) and achieved ratings of $100 \%$ for sensitivity, specificity, consistency and validity. The sera were tested in duplicate. For each sample two aliquots of $150 \mu \mathrm{l}$ were pre-incubated with, and two aliquots without, excess unlabelled recombinant human insulin (Actrapid HM, Novo Nordisk, Gentofte, Denmark) for $60 \mathrm{~min}$ at $4{ }^{\circ} \mathrm{C} .{ }^{125}$ I labelled porcine insulin (Ventrex Laboratories, Portland, Me., USA) was then added to all tubes and incubated for 7 days at $4^{\circ} \mathrm{C}$. Twelve randomly selected tubes were counted for total radioactivity. Antibody bound insulin was then precipitated with polyethylene glycol in Veronal buffer ( $\mathrm{pH} \mathrm{8.6)} \mathrm{and} \mathrm{the} \mathrm{pellet}$ 
from each tube was counted. The percentage of the labelled insulin bound by the serum was then calculated for each tube and the difference was determined between the tubes pre-incubated with and without unlabelled insulin. This difference was multiplied by the amount of unlabelled insulin originally added to the tubes to give the amount of insulin bound by the serum, expressed in $\mathrm{nU} / \mathrm{ml}$ of serum. A reference range was determined by testing 90 non-diabetic children with no evidence of autoimmune disease or family history of diabetes. The IAA levels in these subjects were normally distributed with a mean of $4.2 \mathrm{nU} / \mathrm{ml}$ and SD $9.2 \mathrm{nU} / \mathrm{ml}$. Results greater than $3 \mathrm{SD}$ above the mean $(33 \mathrm{nU} / \mathrm{ml})$ were considered positive.

Thyroid peroxidase autoantibodies. Autoantibodies to thyroid peroxidase (anti-TPO) were measured with an enzyme-linked immunosorbent assay (ELISA) (ELItest anti-TPO, Henning, Berlin, Germany) on 266 samples. Anti-TPO in the sera bind to native human thyroid peroxidase coated onto the wells of a microtitre plate and are detected with protein A conjugated to alkaline phosphatase. Among 50 non-diabetic children, anti-TPO levels were unmeasurable $(<50 \mathrm{U} / \mathrm{ml})$ in all except four individuals (with normal thyroid function tests), who had levels of 54, 56, 59 and $92 \mathrm{U} / \mathrm{ml}$. Results greater than $100 \mathrm{U} /$ $\mathrm{ml}$ were considered positive, in agreement with the reference range for adults suggested by the manufacturer $(0-100 \mathrm{U} / \mathrm{ml})$.

Antigliadin antibodies. Antigliadin IgA antibodies (AGA) by ELISA (Gluten IgA-EIA; Pharmacia Diagnostics, Uppsala, Sweden) [9] were measured on all sera. AGA bind to gliadin coated onto a microtitre well and are detected with a rabbit anti-human $\operatorname{IgA}$ conjugated to $\beta$-galactosidase. The reference range is 0-24 units [10].

Anti-endomysial antibodies. Anti-endomysial $\operatorname{IgA}$ antibodies (AEA) were measured on 271 sera by indirect immunofluorescence on frozen sections of monkey oesophagus (Inova Diagnostics; San Diego, Calif., USA). Sera were diluted 1:5 in PBS at $\mathrm{pH} 7.4$ and $25 \mu \mathrm{l}$ was incubated on the tissue sections in a moisture chamber for $30 \mathrm{~min}$. The sections were washed twice with PBS and incubated for $30 \mathrm{~min}$ with $25 \mu \mathrm{l}$ of fluoresceintagged goat anti-human IgA (Kallestad, Austin, Tex., USA) diluted 1:8 in PBS. After washing again, the sections were observed with a fluorescence microscope (Leitz Ortholux II with a $150 \mathrm{~W}$ xenon fluorescence burner and Plan Apo 25/0.65 objective) and scored as positive or negative [11]. Positive sera were later serially diluted to determine the end-point titre. Ten control children were all negative. Positive and negative control sera were included in each assay.

\section{Statistical analysis}

None of the autoantibody levels was normally distributed, except for the IAA levels in the control group. IAA levels in the cases normalised after $\log$ transformation. Statistical analysis was with Spearman's rank correlation, the chi-squared test, the Mantel-Haenszel chi-squared test and Wilcoxon's rank sum test. For the log-transformed IAA data, linear regression and Pearson's correlation were used. Before log-transformation, negative and zero values of IAA were assigned the value of one to avoid losing information from these data points. Probability values greater than 0.05 were regarded as not statistically significant.

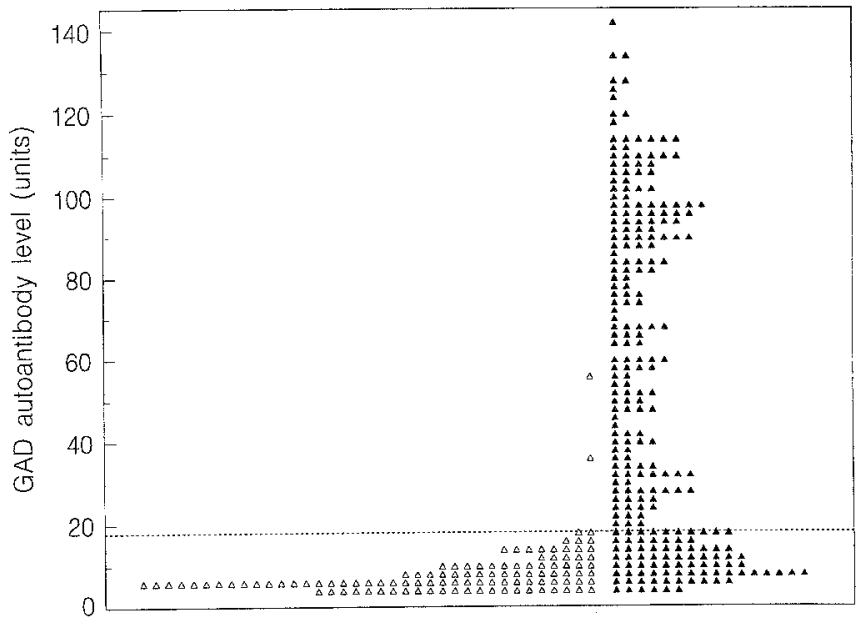

Fig. 1. The levels of antibodies to glutamate decarboxylase (anti-GAD) in 109 non-diabetic children $(\triangle)$ and 261 newlydiagnosed diabetic children $(\boldsymbol{A})$. The dashed line represents the 98 th percentile for anti-GAD among the non-diabetic children (18 units)

\section{Results}

Frequency and levels of autoantibodies. Overall, antiGAD (> 18 units) were detected in $69 \%$ of cases, ICA $(\geqslant 20 \mathrm{JDF}$ U) in $71 \%$ and IAA $(\geqslant 33 \mathrm{nU} / \mathrm{ml})$ in $65 \%$. The median level of anti-GAD was 47 units (interquartile range: 15 to 90) (Fig.1). The titre of ICA was 20 to $39 \mathrm{JDF} U$ in $22 \%$ of the cases, 40 to $79 \mathrm{JDF} \mathrm{U}$ in $35 \%$, and $\geqslant 80 \mathrm{JDF} \mathrm{U}$ in $14 \%$. The median level of IAA was $83 \mathrm{nU} / \mathrm{ml}$ (interquartile range: 23 to 279 ).

Ten percent of the cases ( 13 male, 14 female) were anti-TPO positive $(>100 \mathrm{U} / \mathrm{ml})$ and among positive cases the median level of anti-TPO was 1369 (interquartile range: 509-3317). None of the patients had any symptoms of thyroid disease. Thyroid function tests were performed on 21 of 27 cases positive for anti-TPO and two were hypothyroid, with an elevated level of thyroid stimulating hormone and a decreased level of free thyroxine.

AGA were positive in $2.6 \%$ of the cases and AEA in $3.0 \%$. For five patients $(1.8 \%)$, ranging in age from 7.3 to 13.9 years, there was a clear elevation of both AGA (range: 43-225 units) and AEA levels (titre of 1:160). Although asymptomatic, all five were later found to have abnormalities on small bowel biopsy diagnostic of coeliac disease and were treated with a gluten-free diet. Another three patients had a borderline elevation of AGA (highest 27 units) or equivocal AEA. Three of these had antibody levels repeated at a later time point, and all were negative.

Associations with age and gender. Figure 2 shows the percentage of the cases positive for autoantibodies by age at diagnosis. IAA were more frequent in 


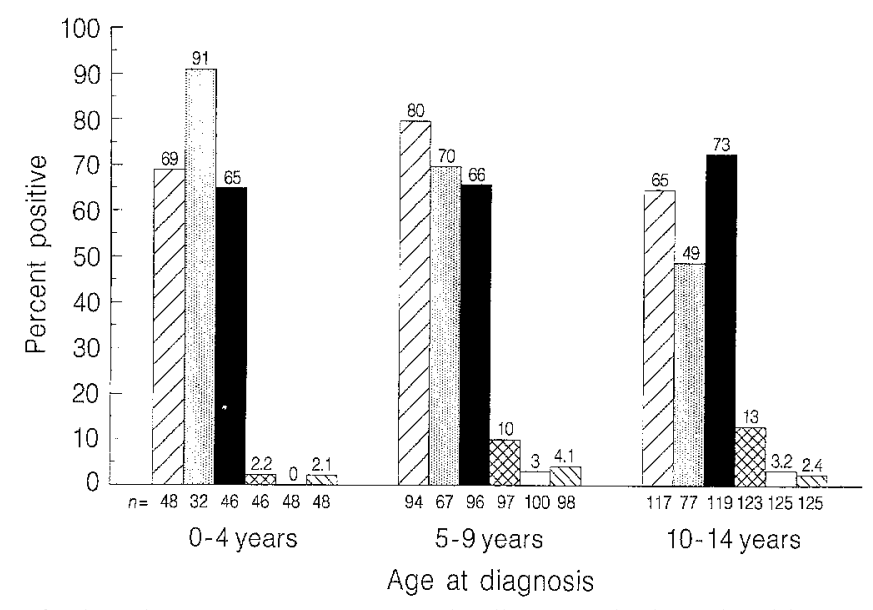

Fig. 2. The percentage of newly-diagnosed diabetic children positive for autoantibodies, according to age at diagnosis. (ICA, islet cell antibodies $\square$; IAA, insulin autoantibodies anti-GAD, glutamate decarboxylase autoantibodies $\square$; antiTPO, thyroid peroxidase autoantibodies AGA, antigliadin IgA antibodies $\square$; AEA, antiendomysial antibodies $\mathbb{N}$ ). The number of patients analysed is given below each bar. IAA levels on sera collected more than 4 days after the start of insulin therapy were excluded from analysis

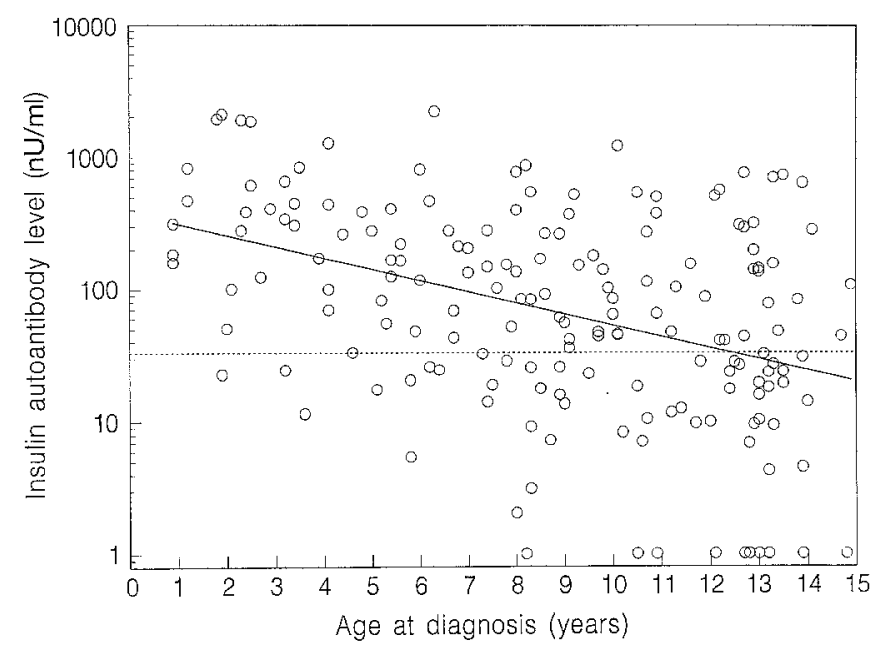

Fig. 3. The insulin autoantibody level (IAA), on a logarithmic scale, plotted against the age at diagnosis in 176 newly-diagnosed diabetic children. The dashed line represents the cutoff for IAA positivity $(33 \mathrm{nU} / \mathrm{ml})$ and the solid line represents the linear regression of $\log _{10}$ IAA on age at diagnosis $\left(R^{2}=0.17, p<0.0001\right)$

younger age groups (Mantel-Haenszel $\chi^{2}$ for trend $=18.14, p<0.0001$ ) and there was a negative correlation between the level of IAA ( $\log _{10}$-transformed) and age at diagnosis $(r=-0.41, p<0.0001$, Pearson correlation) (Fig. 3). There was no significant correlation between the level of anti-GAD and age at diagnosis $(r=0.05, p=0.4)$. A higher frequency of anti-TPO was found with increasing age (Mantel-Haenszel $\chi^{2}$ for trend $=3.84, p=0.05$ ). There was no significant association between the frequency of ICA, anti-GAD, AGA or AEA and age at diagnosis.

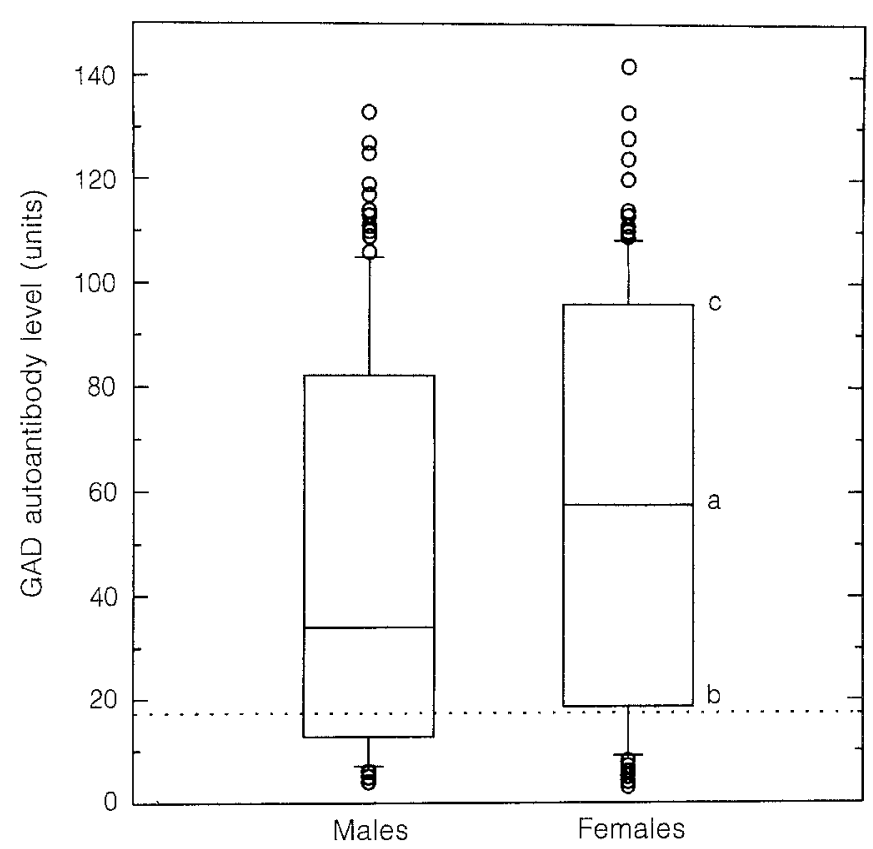

Fig. 4. Comparison of the glutamate decarboxylase autoantibody levels in 129 male and 132 female newly-diagnosed diabetic children. The dashed line represents the cut-off for antiglutamate decarboxylase autoantibody (GAD) positivity (18 units). Each box plot shows the median (a), 25th (b) and 75th (c) centiles for anti-GAD. The error bars show the 10th and 90th centiles. Data points below the 10th or above the 90th centile are shown individually

Figure 4 shows a sex difference in anti-GAD that was not found for the other antibodies. The levels of anti-GAD were higher among girls (median 57.5 units, interquartile range: 18.5 to 96 ) than boys (median 34 units, interquartile range: 13 to 82 ) ( $p=0.02$, Wilcoxon test). Similarly, $75 \%$ of the girls were anti-GAD positive compared with $63 \%$ of the boys $(p=0.03)$.

Associations with family history, season, geographical area and ethnic background. A history of IDDM in a first degree relative was present in $6.9 \%$ of cases. There were no significant differences in the frequencies of any of the autoantibodies between cases with and without an affected first degree relative. There were no significant differences with respect to season of onset, geographical area of residence at the time of diagnosis or ethnic background.

Associations between autoantibodies. Higher titres of ICA were associated with a greater frequency of anti-GAD (Mantel-Haenszel $\chi^{2}$ for trend $=19.24$, $p<0.0001$ ) and higher levels of anti-GAD (Fig.5). Figure 6 shows a similar but less prominent association between IAA and ICA (Mantel-Haenszel $\chi^{2}$ for trend $=8.64, p=0.003$ ). However, there was no significant association between the levels of anti-GAD and IAA $(r=0.06, p=0.5)$. Among cases positive for anti-GAD, $12.4 \%$ (22 of 177 ) were positive for 


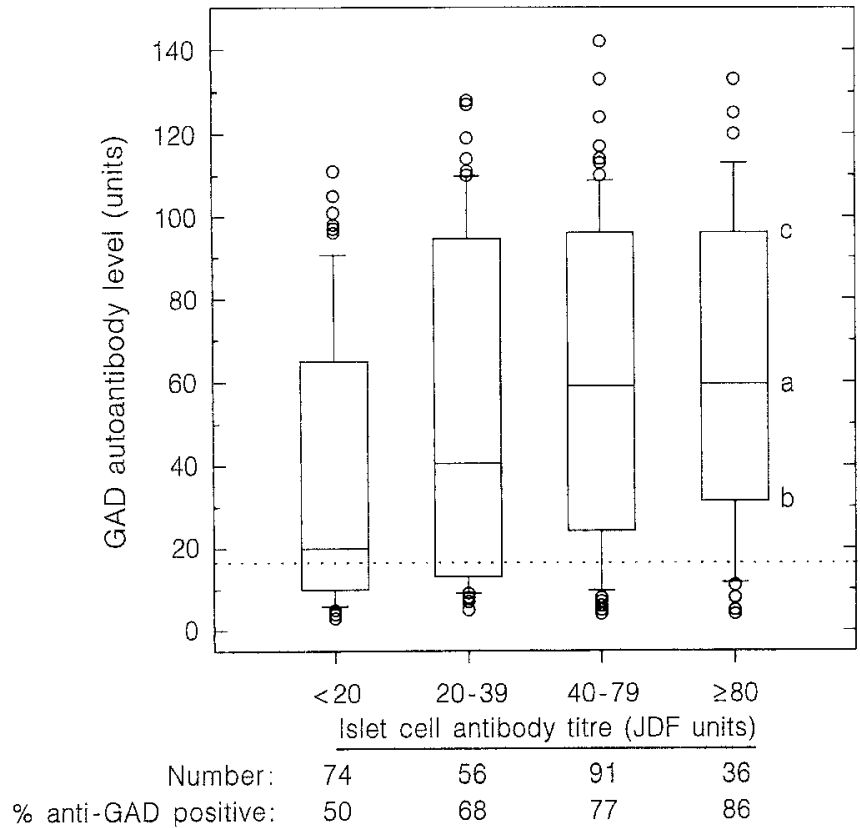

Fig. 5. The relationship between the glutamate decarboxylase antibody level (anti-GAD) and the islet cell antibody titre (ICA) in 257 newly-diagnosed diabetic children. The dashed line represents the cut-off for anti-GAD positivity (18 units). Each box plot shows the median (a), 25th (b) and 75th (c) centiles for anti-GAD. The error bars show the 10th and 90th centiles. Data points below the 10 th or above the 90 th centile are shown individually

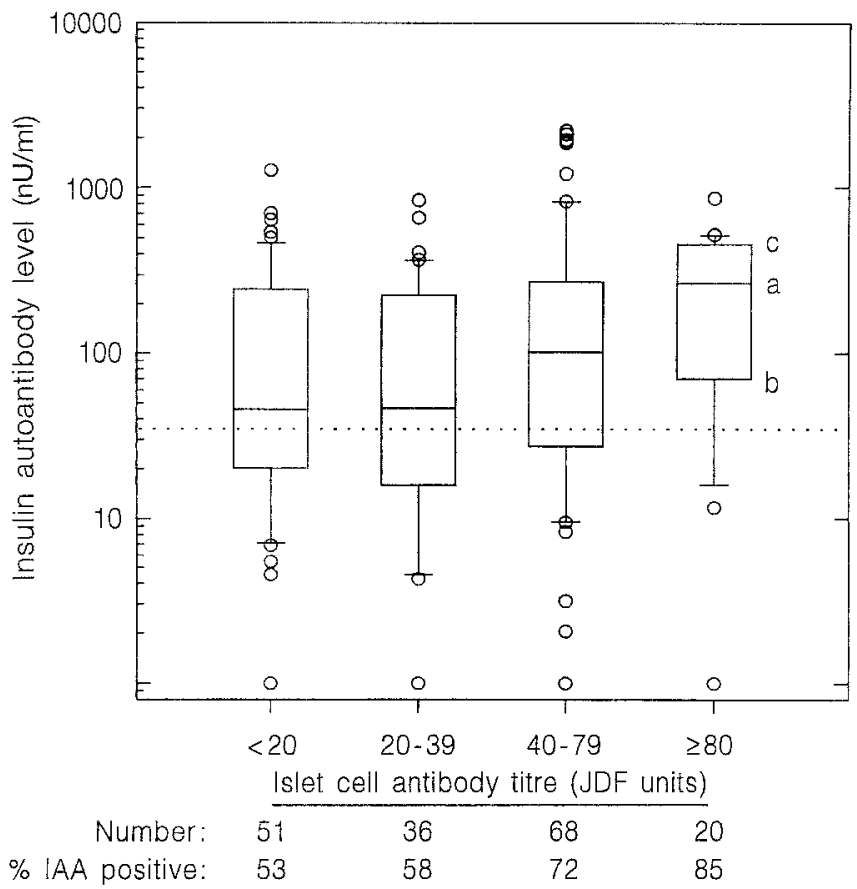

Fig. 6. The relationship between the insulin autoantibody level (IAA) and the islet cell antibody titre (ICA) in 175 newly-diagnosed diabetic children. The dashed line represents the cut-off for IAA positivity $(33 \mathrm{nU} / \mathrm{ml})$. Each box plot shows the median (a), 25th (b) and 75 th (c) centiles for anti-GAD. The error bars show the 10 th and 90 th centiles. Data points below the 10 th or above the 90 th centile are shown individually

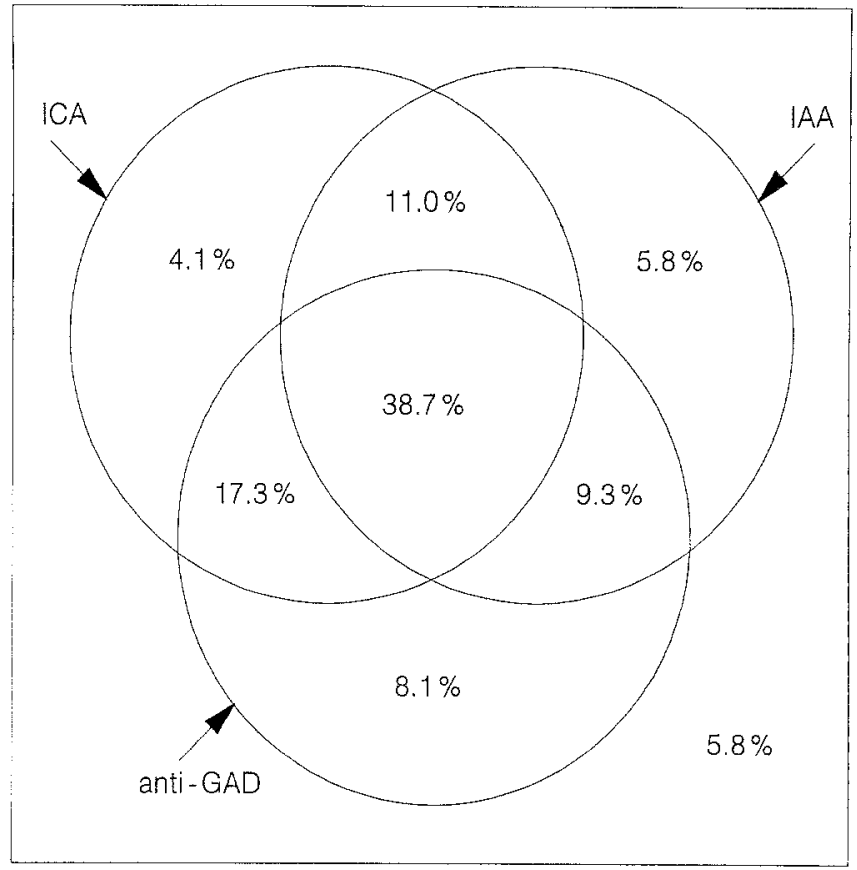

Fig. 7. The percentage of newly-diagnosed diabetic children positive for each combination of islet cell antibodies (ICA), insulin autoantibodies (IAA) and glutamate decarboxylase autoantibodies (anti-GAD). The results are shown for 173 children with measurements of all three autoantibodies

anti-TPO, compared with only $4.9 \%$ ( 4 of 77 ) among cases negative for anti-GAD, although this difference was not statistically significant $(p=0.06)$.

Results for both ICA and IAA were available for 175 cases and, of these, $24(13.7 \%)$ were negative for both markers. In comparison, results for all three autoantibodies (ICA, IAA and anti-GAD) were available for 173 cases (Fig. 7) and only $10(5.8 \%)$ were negative for all three markers. These triple negative cases were not significantly different from the remainder in terms of age, sex or the presence of other antibodies (anti-TPO, AGA and AEA).

\section{Discussion}

We studied newly-diagnosed diabetic children from a large population-based register and found that $69 \%$ were positive for anti-GAD, $71 \%$ for ICA, and $65 \%$ for IAA. Only $5.8 \%$ were negative for all three markers. The addition of anti-GAD as a serological marker to the combination of ICA and IAA more than halved the number of autoantibody negative children.

Other studies have reported varying frequencies of ICA in newly-diagnosed diabetic children, ranging from $54 \%$ to $94 \%[5,7,12-15]$. This may be partly explained by differences in sensitivity between laboratories and by inter-laboratory variation in ICA measurements, despite improvement after standardi- 
sation workshops [16-19]. A limiting factor may be variation in the pancreatic substrate, as major differences have been reported in the results (standardised in JDF U) obtained with different pancreases in the same assay [20]. The radioimmunoprecipitation assay for anti-GAD used in this study does not have these limitations [2].

The ICA assay is likely to measure antibodies against several different islet antigens. Our finding of a strong association between ICA titres and antiGAD levels is consistent with evidence that GAD is an ICA antigen [21-23]. We also found an association between ICA titre and IAA level. Insulin does not stain on frozen pancreatic sections but IAA cross-react with proinsulin [24], which can be immunostained on frozen sections [25]. The other autoantigen(s) accounting for the remainder of ICA staining remain to be identified and biochemically characterised. A ganglioside [26] and other recently discovered autoantigens [27-30] are candidates.

Vardi et al. [8, 13] found IAA in 50-69\% of newly diagnosed patients aged under 32 years, similar to the prevalence of $65 \%$ that we found in newly-diagnosed children. We confirmed previous findings that IAA occur more frequently, and at higher levels, in younger children $[13,15,31,32]$. In agreement with other studies, we found no association between ICA titre and age at diagnosis $[7,12,13]$, although a lower frequency of ICA has been reported among older adult patients with newly-diagnosed IDDM, especially in men [33]. There were no significant age differences in the frequency or level of anti-GAD among the children we studied.

Other studies, using different assay formats and involving smaller numbers of recently-diagnosed patients of all ages, have reported frequencies of antiGAD varying from 25 to $70 \%$ [14, 34-37], compared with the frequency of $69 \%$ that we found in children. This may reflect differences in assay sensitivity. We found a higher frequency and higher levels of anti-GAD in females than in males, in agreement with two other studies [34, 38]. Martino et al. [34] found a significantly higher frequency of anti-TPO among anti-GAD positive than among anti-GAD negative adults with newly-diagnosed IDDM and suggested that this may represent a subgroup associated with polyendocrine autoimmunity. There was a similar association in the children we studied, although this was not statistically significant.

Immune-mediated diseases that may coexist with IDDM include thyroiditis and coeliac disease. We found that $10 \%$ of newly-diagnosed diabetic children were positive for anti-TPO, a sensitive and specific marker of thyroid autoimmunity $[39,40]$. There was a significantly higher frequency in older than in younger children. Studies in adult IDDM patients without clinical or biochemical evidence of thyroid dysfunction have reported positive levels in 18 to
$24 \%[39,40]$. A minority of children with anti-TPO in our study had evidence of thyroid dysfunction, but the presence of this antibody indicates a high risk for future hypothyroidism [41, 42]. Coeliac disease was present in at least $1.8 \%$ of the children we studied. Other studies, not restricted to newly-diagnosed patients, have found prevalence rates ranging from 1.5 to $3.5 \%$ [43-48]. Antigliadin IgA is of greater value than antigliadin $\mathrm{IgG}$ as a screening test for coeliac disease $[44,45,49]$. However, antigliadin IgA may be falsely negative in patients with IgA deficiency, which occurs in approximately $2.5 \%$ of children with IDDM [50] and with increased frequency in coeliac disease. Both antigliadin IgA (AGA) and anti-endomysial IgA antibodies (AEA) have been reported to have high sensitivity and specificity $[9,51]$. We found that AGA was of equal value to AEA when screening diabetic children, and it has the advantage of an ELISA format, suitable for handling large numbers of samples.

In conclusion, we found a high frequency of antiGAD in children with newly-diagnosed IDDM. The addition of anti-GAD as a serological marker to the combination of ICA and IAA more than halved the number of autoantibody negative children and only $5.8 \%$ were negative for all three serological markers. There was a higher frequency of anti-GAD in girls than in boys, a higher frequency of IAA in younger patients and a higher frequency of antiTPO in older patients. Asymptomatic coeliac disease occurred in at least $1.8 \%$ of newly-diagnosed diabetic children.

Acknowledgements. We are indebted to the many physicians, diabetes educators and nurses who sent us sera and information on their patients. We are grateful to the Biochemistry Laboratory, Royal Alexandra Hospital for Children, Sydney for performing the antigliadin IgA antibody assays and to C.C. Pilcher, R.B. Elliott (Department of Paediatrics, University of Auckland), P.G. Colman, J.Caudwell (Endocrinology Laboratory, Royal Melbourne Hospital), S. Pummer (Department of Clinical Immunology, Sir Charles Gairdner Hospital, Perth) and the Red Cross Histocompatibility Committee for Organ Transplantation in Sydney for assistance in setting up the ICA assay.

\section{References}

1. Bingley PJ, Bonifacio E, Gale EAM (1993) Perspectives in diabetes. Can we really predict IDDM? Diabetes 42:213220

2. Rowley MJ, Mackay IR, Chen Q-Y, Knowles WJ, Zimmet PZ (1992) Antibodies to glutamic acid decarboxylase discriminate major types of diabetes mellitus. Diabetes 41:548-551

3. Verge CF, Silink M, Howard NJ (1994) The incidence of childhood IDDM in New South Wales, Australia. Diabetes Care 17:693-696

4. LaPorte RE, McCarty D, Bruno G, Tajima N, Baba S (1993) Counting diabetes in the next millenium. Applica- 
tion of the capture-recapture technology. Diabetes Care 16:528-534

5. Kolb H, Dannehl K, Grueneklee D et al. (1988) Prospective analysis of islet cell antibodies in children with type 1 (insulin-dependent) diabetes. Diabetologia 31:189-194

6. Australian Bureau of Statistics (1992) 1991 Census of population and housing: age and sex in statistical local areas in NSW. ABS, Sydney

7. Pilcher CC, Elliott RB (1990) A sensitive and reproducible method for the assay of human islet cell antibodies. J Immunol Methods 129:111-117

8. Vardi P, Dib SA, Tuttleman M et al. (1987) Competitive insulin autoantibody assay: prospective evaluation of subjects at high risk for development of type I diabetes mellitus. Diabetes 36:1286-1291

9. Ascher H, Lanner A, Kristiansson B (1990) A new laboratory kit for anti-gliadin $\operatorname{IgA}$ at diagnosis and follow-up of childhood celiac disease. J Pediatr Gastroenterol Nutr 10:443-450

10. Juto P, Almlof U, Hernell O, Kober A, Ahlstedt S (1987) Evaluation of antigliadin IgA as a screening method for coeliac disease in children. Pediatr Res 22:234 (Abstract)

11. Kapuscinska A, Zalewski T, Chorzelski TP et al. (1987) Disease specificity and dynamics of changes in $\operatorname{IgA}$ class anti-endomysial antibodies in celiac disease. J Pediatr Gastroenterol Nutr 6:529-534

12. Landin-Olsson M, Karlsson A, Dahlquist G et al. (1989) Islet cell and other organ-specific autoantibodies in all children developing type 1 (insulin-dependent) diabetes mellitus in Sweden during one year and in matched control children. Diabetologia 32:387-395

13. Vardi P, Ziegler AG, Matthews JH et al. (1988) Concentration of insulin autoantibodies at onset of type I diabetes: inverse log-linear correlation with age. Diabetes Care 11:736-739

14. Thivolet CH, Tappaz M, Durand A et al. (1992) Glutamic acid decarboxylase (GAD) autoantibodies are additional predictive markers of type 1 (insulin-dependent) diabetes mellitus in high risk individuals. Diabetologia 35:570--576

15. Karjalainen J, Knip M, Mustonen A, Ilonen J, Åkerblom HK (1986) Relation between insulin antibody and complement-fixing islet cell antibody at clinical diagnosis of IDDM. Diabetes 35:620-622

16. Bottazzo GF, Gleichmann H (1986) Immunology and diabetes workshops: report of the first international workshop on standardization of cytoplasmic islet cell antibodies. Diabetologia 29:125

17. Bonifacio E, Lernmark $\AA$, Dawkins RL et al. (1988) Serum exchange and use of dilutions have improved precision of measurement of islet cell antibodies. J Immunol Methods $106: 83-88$

18. Boitard C, Bonifacio G, Bottazzo GF, Gleichman H, Molenaar J (1988) Immunology and diabetes workshop: report on the third international (stage 3) workshop on the standardisation of cytoplasmic islet cell antibodies. Diabetologia 31:451-452

19. Greenbaum CJ, Palmer JP, Nagataki S et al. (1992) Improved specificity of ICA assays in the fourth international immunology of diabetes exhange workshop. Diabetes 41:1570-1574

20. Landin-Olsson M (1990) Precision of the islet-cell antibody assay depends on the pancreas. J Clin Lab Anal $4: 289-294$

21. Gianani R, Pugliese A, Bonner-Weir S et al. (1992) Prognostically significant heterogeneity of cytoplasmic islet cell antibodies in relatives of patients with type I Diabetes. Diabetes $41: 347-353$
22. Genovese S, Bonifacio E, McNally JM et al. (1992) Distinct cytoplasmic islet cell antibodies with different risks for type I (insulin-dependent) diabetes mellitus. Diabetologia 35:385-388

23. Gianani R, Jackson R, Eisenbarth GS (1991) Evidence that the autoantigen of restricted ICA is GAD. Diabetes Res Clin Pract 14 [Suppl 1]:S13 (Abstract)

24. Bohmer K, Keilacker H, Kuglin B et al. (1991) Proinsulin autoantibodies are more closely associated with type 1 (insulin-dependent) diabetes mellitus than insulin autoantibodies. Diabetologia 34:830-834

25. Madsen OD, Landin-Olsson M, Bille G et al. (1986) A twocolour immunofluorescence test with monoclonal human proinsulin antibody improves the assay for islet cell antibodies. Diabetologia 29:115-118

26. Colman PG, Nayak RC, Campbell IL, Eisenbarth GS (1988) Binding of cytoplasmic islet cell antibodies is blocked by human pancreatic glycolipid extracts. Diabetes 37:645-652

27. Castano L, Russo E, Zhou L, Lipes MA, Eisenbarth GS (1991) Identification and cloning of a granule autoantigen (carboxypeptidase $\mathbf{H}$ ) associated with type I diabetes. J Clin Endocrinol Metab 73:1197-1201

28. Pietropaolo M, Castano L, Babu S et al. (1993) Islet cell autoantigen $69 \mathrm{kDa}$ (ICA69): Molecular cloning and characterization of a novel diabetes associated autoantigen. $J$ Clin Invest 92:359-371

29. Christie MR, Tun RYM, Lo SSS et al. (1992) Antibodies to $\mathrm{GAD}$ and tryptic fragments of islet $64 \mathrm{~K}$ antigen as distinct markers for development of IDDM: studies with identical twins. Diabetes 41:782-787

30. Roep BO, Kallan AA, Hazenbos WLW et al. (1991) T-cell reactivity to a $38 \mathrm{kD}$ insulin-secretory-granule protein in patients with recent-onset type 1 diabetes. Lancet 337:1439-1441

31. Arslanian SL, Becker DJ, Rabin B et al. (1985) Correlates of insulin antibodies in newly diagnosed children with insulin-dependent diabetes before insulin therapy. Diabetes 34:926-930

32. McEvoy RC, Witt ME, Ginsberg-Fellner F, Rubenstein P (1986) Anti-insulin antibodies in children with type I diabetes. Diabetes 35:634-641

33. Landin-Olsson M, Karlsson FA, Lernmark $\AA$, Sundkvist G, and the Diabetes Incidence Study in Sweden Group (1992) Islet cell and thyrogastric antibodies in 633 consecutive 15to 34-yr-old patients in the diabetes incidence study in Sweden. Diabetes 41:1022-1027

34. Martino GV, Tappaz ML, Braghi S et al. (1991) Autoantibodies to glutamic acid decarboxylase (GAD) detected by an immuno-trapping enzyme activity assay: relation to insulin-dependent diabetes mellitus. J Autoimmunity 4:915-923

35. DeAizpurua HJ, Harrison LC, Cram DS (1992) An ELISA for antibodies to recombinant glutamic acid decarboxylase in IDDM. Diabetes 41:1182-1187

36. DeAizpurua HJ, Wilson Y, Harrison LC (1992) Glutamic acid decarboxylase (GAD) autoantibodies in preclinical insulin-dependent diabetes. Proc Natl Acad Sci USA 89:9841-9845

37. Hagopian WA, Karlsen AE, Gottsater A et al. (1993) Quantitative assay using recombinant human islet glutamic acid decarboxylase (GAD65) shows that $64 \mathrm{~K}$ autoantibody positivity at onset predicts diabetes type. J Clin Invest 91:368-374

38. Chen Q-Y, Rowley MJ, Byrne GC et al. (1993) Antibodies to glutamic acid decarboxylase in Australian children with insulin dependent diabetes mellitus and their first degree relatives. Pediatr Res 34:785-790 
39. Feldt-Rasmussen U, Hoier-Madsen M, Bech K et al. (1991) Anti-thyroid peroxidase antibodies in thyroid disorders and non-thyroid autoimmune diseases. Autoimmunity 9:245-253

40. Doullay F, Ruf J, Codaccioni J-L, Carayon P (1991) Prevalence of autoantibodies to thyroperoxidase in patients with various thyroid and autoimmune diseases. Autoimmunity 9:237-244

41. Riley WJ, Maclaren NK, Lezotte DC, Spillar RP, Rosenbloom AL (1981) Thyroid autoimmunity in insulin-dependent diabetes mellitus: the case for routine screening. J Pediatr 99:350-354

42. Maclaren NK, Riley WJ (1985) Thyroid, gastric, and adrenal autoimmunities associated with insulin-dependent diabetes mellitus. Diabetes Care 8 [Suppl 1]:34-38

43. Gadd S, Kamath KR, Silink M, Skerritt JH (1992) Co-existence of coeliac disease and insulin-dependent diabetes mellitus in children: screening sera using an ELISA test for gliadin antibody. Aust N Z J Med 22:256-260

44. Barera G, Bianchi C, Calisti L et al. (1991) Screening of diabetic children for coeliac disease with antigliadin antibodies and HLA typing. Arch Dis Child 66:491-494

45. Savilahti E, Simell O, Koskimies S, Rilva A, Åkerblom HK (1986) Celiac disease in insulin-dependent diabetes mellitus. J Pediatr 108:690-693
46. Cacciari E, Salardi S, Volta U et al. (1987) Prevalence and characteristics of coeliac disease in type 1 diabetes mellitus. Acta Paediatr Scand 76:671-672

47. Maki M, Hallstrom O, Huupponen T, Vesikari T, Visakorpi JK (1984) Increased prevalence of coeliac disease in diabetes. Arch Dis Child 59:739-742

48. Thain ME, Hamilton JR, Ehrlich RM (1974) Coexistence of diabetes mellitus and celiac disease. J Pediatr 85:527-529

49. McMillan SA, Haughton DJ, Biggart JD, Edgar JD, Porter KG, McNeill TA (1991) Predictive value for coeliac disease of antibodies to gliadin, endomysium, and jejunum in patients attending for jejunal biopsy. BMJ 303:1163-1165

50. Smith WI, Rabin BS, Huellmantel A, VanThiel DH, Drash A (1978) Immunopathology of juvenile-onset diabetes mellitus: 1 . IgA deficiency and juvenile diabetes. Diabetes 27:1092-1097

51. Rossi TM, Kumar V, Lerner A, Heitlinger LA, Tucker N, Fisher J (1988) Relationship of endomysial antibodies to jejunal mucosal pathology: specificity towards both symptomatic and asymptomatic celiacs. J Ped Gastro Nutrition $7: 858-863$ 